\title{
Serum creatinine concentration in very-low-birth-weight infants from birth to 34-36 wk postmenstrual age
}

\author{
David A. Bateman ${ }^{1}$, William Thomas ${ }^{2}$, Elvira Parravicini' ${ }^{1}$ Elena Polesana ${ }^{1}$, Chiara Locatelli ${ }^{3}$ and John M. Lorenz ${ }^{1}$
}

BACKGROUND: Serum creatinine $(\mathrm{s}[\mathrm{Cr}])$ reference ranges for very-low-birth-weight (VLBW) infants must account for physiologic changes in the first months of life.

METHODS: We retrospectively identified a sample of 218 appropriate-for-gestational age (GA) VLBW infants without risk factors for renal impairment, and classified into one of three GA groups: 25-27, 28-29, and 30-33wk. We observed three phases of s[Cr] change (initial, decline, and equilibrium), whose characteristics varied by GA group. We used mixed-effects regression models to estimate mean and upper 95th prediction interval of s[Cr] for each GA group from birth to 34-36 wk post menstrual age (PMA).

RESULTS: In phase I, s[Cr] increased after birth, then returned slowly to baseline. The duration of phase I and the magnitude of $s[\mathrm{Cr}]$ rise decreased with increasing $\mathrm{GA}$. In phase $\mathrm{II}, \mathrm{s}[\mathrm{Cr}]$ declined abruptly at a rate that increased with GA. A gradual transition to phase III, a steady-state equilibrium with similar $s[\mathrm{Cr}]$ among GA groups, began at approximately 34-36wk PMA. We constructed GA group-specific nomograms depicting $\mathrm{s}[\mathrm{Cr}]$ behaviour across the three phases.

CONCLUSION: The reference ranges derived from a sample of infants without risk factors for renal impairment provide a context for quantitative interpretation of $s[C r]$ trends in VLBW infants.

$S^{\mathrm{e}}$ erum creatinine concentration $(\mathrm{s}[\mathrm{Cr}])$ is the most widely used marker of renal function, specifically to make inferences about glomerular filtration rate (GFR). In very-low-birthweight (VLBW) preterm infants, interpretation of a single $s[\mathrm{Cr}]$ is problematic. $\mathrm{S}[\mathrm{Cr}]$ changes markedly after birth, reflecting the dynamic interaction of maternal renal function, neonatal muscle mass, GFR, and slowly-maturing glomerular and tubular function, precluding a single reference range for $\mathrm{s}[\mathrm{Cr}]$ values (1-11). Definitions of acute kidney injury (AKI) in the newborn based on an absolute change in $s[\mathrm{Cr}]$ may not account for physiologic changes in $s[\mathrm{Cr}]$. For example, the absence of a physiologic decline in $\mathrm{s}[\mathrm{Cr}]$ during the first month of life may represent diminished renal function. Thus, it is imperative that reference ranges accounting for physiologic changes in $s[\mathrm{Cr}]$ be defined $(12,13)$. Although studies have described changes in
$s[\mathrm{Cr}]$ after birth in preterm infants, their samples have often included infants with risk factors for renal impairment or have not been presented in a way that allows $\mathrm{s}[\mathrm{Cr}] \mathrm{s}$ outside a normal reference range to be easily recognized. Only a few studies have examined how gestational age (GA) influences the chronological age at which $s[\mathrm{Cr}]$ equilibrium is reached $(8,11)$.

We report estimates of mean and upper 95th prediction interval of $s[\mathrm{Cr}]$ for VLBW infants with uncomplicated clinical courses as functions of gestational and postnatal age from birth to $34-36 \mathrm{wk}$ postmenstrual age (PMA). Because the assessment of the pattern and progression of $s[\mathrm{Cr}]$ may be of far more interest to a clinician than an individual $s[\mathrm{Cr}]$ value, our goal was to create reference ranges that allow the assessment of $s[\mathrm{Cr}]$ trends.

\section{RESULTS}

Table 1 displays selected characteristics of infants born during the study period who were included and not included in the study. The excluded infants had significantly lower GA and birth weight (BW), and were more likely to receive positive pressure resuscitation at birth, surfactant treatment, and mechanical ventilation than the included infants. These differences reflect the increased probability of exclusion on the basis of risk for AKI among sicker, smaller infants and with lower BW and GA.

\section{Phases of Mean s[Cr]}

Panels (a)-(c) of Figure 1 show mean s[Cr] and 95\% prediction levels by GA group and the overlying profiles of $s[\mathrm{Cr}]$ for each infant in the group. In the week after birth, $s[\mathrm{Cr}]$ is highest and most variable, then declines rapidly over 3-6wk, approaching a stable level with lower variability thereafter. The profile of $s[\mathrm{Cr}]$ behaviour after birth falls into three distinct phases whose characteristics vary with GA.

Phase I (initial postnatal). Mean $\mathrm{s}[\mathrm{Cr}]$ increases during the first 3-4 postnatal days by $10-25 \%$ and declines slowly back to baseline over the first week of life in infants born at 25-27 wk. The magnitude of increase is greater at earlier GA. In infants born at $28 \mathrm{wk}$ and later, the duration and magnitude of this initial increase in mean $\mathrm{s}[\mathrm{Cr}]$ progressively diminish. 
Table 1. Selected characteristics of infants included and not included in the study

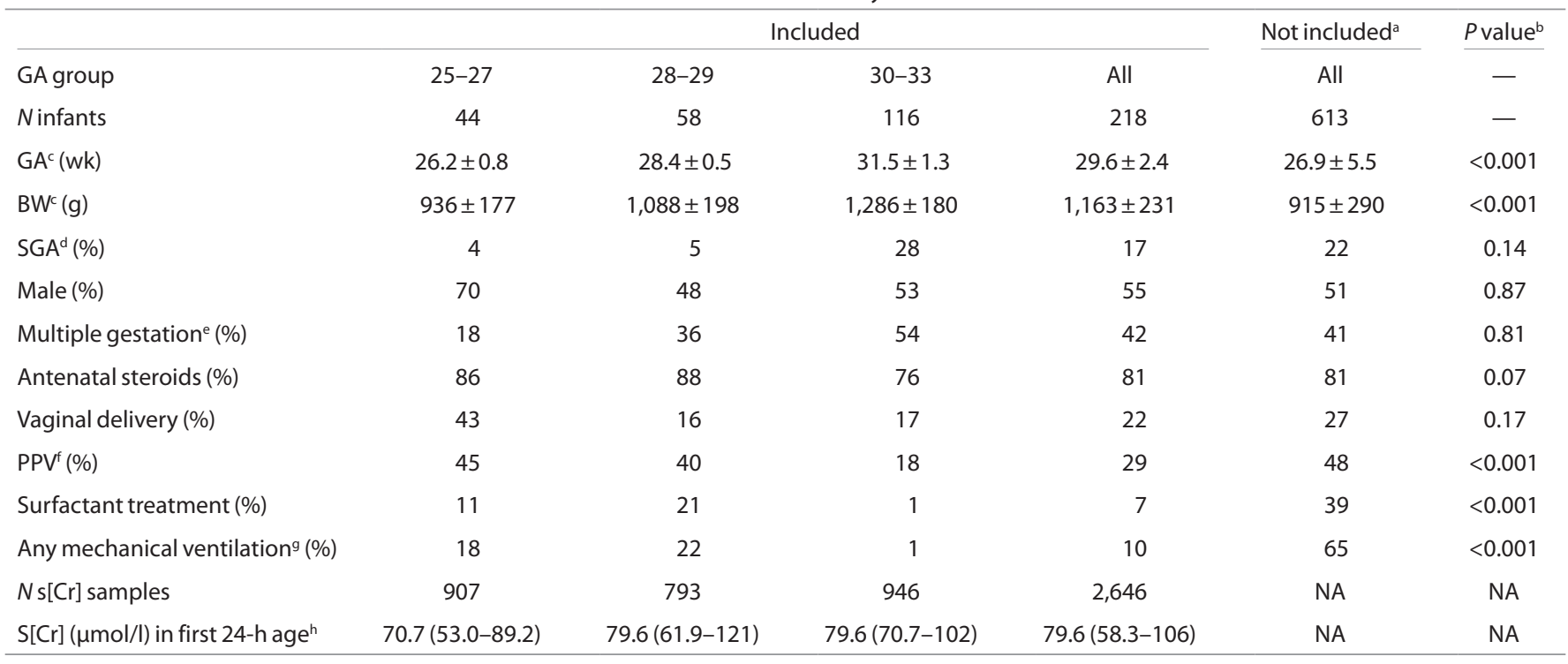

BW, birth weight; GA, gestational age; NA, not pplicable; PPV, positive pressure ventilation; SGA, small for gestational age; S[Cr], serum creatinine.

asee Methods for exclusion criteria. ${ }^{\mathrm{b}} P$ value computed for included $(n=218)$ vs. non-included infants $(n=613)$ using independent samples $t$-test, $\chi^{2}$ analysis with continuity

correction, or Fisher test, as appropriate. cMean \pm (SD). dSGA: birth weight < 10th percentile for GA (39). eln all but five cases, only one member of the multiple set was included in the dataset. PPV: positive pressure ventilation with active lung inflation at delivery. 9During days 1-6. An exclusionary risk factor for sample selection was mechanical ventilation beyond the first $6 \mathrm{~d}$ of age. "Median, 5th-95th percentile range for s[Cr] pooled samples by GA group. S[Cr] differed significantly $(P<0.05)$ between $\mathrm{GA}$ group $25-27$ wk and each of the two other GA groups in Kruskal-Wallis test with posthoc analysis. Differences may reflect normal physiologic progression of maternal s[Cr] during the third trimester of pregnancy (18).

Phase II (rapid decline). Mean $s[\mathrm{Cr}]$ declines rapidly over $3-7 \mathrm{wk}$. In infants born at $25-27 \mathrm{wk}$, the decrease in mean $\mathrm{s}[\mathrm{Cr}]$ begins midway through the first postnatal week and continues for 6-7wk thereafter. In infants born at $28-29 \mathrm{wk}$, mean $\mathrm{s}[\mathrm{Cr}]$ decreases from birth through $6-7 \mathrm{wk}$. Those born at 30-33 wk have the most rapid decline in mean s[Cr] with a duration of only $4-5 \mathrm{wk}$. In summary, mean $\mathrm{s}[\mathrm{Cr}]$ decline begins a few days earlier and declines at a more rapid rate with increasing GA.

Phase III (equilibrium). Mean $\mathrm{s}[\mathrm{Cr}]$ values approach a stable plateau at approximately $24-28 \mu \mathrm{mol} / \mathrm{l}(0.27-0.32 \mathrm{mg} / \mathrm{dl})$, as infants approach a steady state between creatinine production and creatinine excretion. These levels are reached at approximately 8-9, 7-8, and 5-6wk after birth in infants born at $25-27,28-29$, and 30-33 wk, respectively, as shown in Figure 1.

\section{Mean and 95th Percentile s[Cr] Values in Table and Nomograms}

Table 2 displays daily mean and 95th percentile $s[\mathrm{Cr}]$ values by GA group, adjusted for birth weight, gender, and total days of gentamicin. These are displayed graphically in Figure 1. Within each GA group, $s[\mathrm{Cr}]$ values are not reported after the day when there were too few to make reliable variance estimates. In each GA group, $4-6 \%$ of infants had three or more contiguous $s[\mathrm{Cr}]$ measurements above the reported 95th percentile.

\section{Gentamicin Effect}

Most study infants were exposed to gentamicin at some time during their hospitalization, but the exposure rate decreased as GA increased (Table 3). Mean duration of initial exposure and total exposure were highest in the $25-27$ wk GA group.
Because gentamicin exposure was strongly associated with GA group, its effect on $s[\mathrm{Cr}]$ could not be distinguished from the effect of GA group in regression models.

\section{DISCUSSION}

During the first $4-8$ wk of life, the behaviour of $s[\mathrm{Cr}]$ in VLBW infants can be empirically divided into three phases: initial, decline, and equilibrium. Although this pattern has been depicted previously by investigators $(8,9,11,14)$, it is useful to explicitly distinguish these stages in order to emphasize their distinct physiologic differences.

Several major changes in renal function contribute to the patterns of $s[\mathrm{Cr}]$ change. Intense nephrogenesis occurs during the third trimester of gestation, with a normal adult complement of one million nephrons attained by 35-wk GA (5). During this period, GFR increases logarithmically with PMA (7). Postmortem histologic studies on renal tissue from preterm infants demonstrated that nephrogenesis continues after early third-trimester preterm birth, although with a higher number of structurally abnormal glomeruli compared with GA-matched controls $(15,16)$. In utero, newborn $s[\mathrm{Cr}]$ is in equilibrium with maternal $s[\mathrm{Cr}](4,17,18)$. After birth, the factors that contribute to a re-equilibration of $s[\mathrm{Cr}]$ reflecting the infant's own rates of creatinine metabolism and excretion are in flux $(4,17)$. These include changes in systemic blood pressure, renal perfusion, capillary permeability, extracellular fluid volume, and in tubular handling of sodium, potassium, and hydrogen ions, all of which may be modified by systemic illness. Transient reabsorption of $s[\mathrm{Cr}]$ across leaky, immature tubules has been postulated to explain the transient increase in $s[\mathrm{Cr}]$ during the first week of life in very preterm infants (phase I) (19). This effect is more pronounced in more immature 
infants and resolves slowly as renal blood flow and glomerular filtration increase over the first several days of life and tubular function matures.

Other investigators have examined $\mathrm{s}[\mathrm{Cr}]$ behaviour over the first few months of life $(1,3,8,9,11,19-24)$. The domeshaped initial phase in infants of $25-27 \mathrm{wk}$ has been previously described $(1,8,9,11,14)$ with peak $\mathrm{s}[\mathrm{Cr}]$ at about $2-3 \mathrm{~d}$ of age. Miall et al. (1) provided tabular and graphic representations of means and $95 \%$ confidence intervals (CIs) by GA group for this phase. Gallini et al. (8) presented detailed, GA-specific data on $s[\mathrm{Cr}]$ behaviour and $\mathrm{Cr}$ clearance from birth to equilibrium at $6-8$ wk. Gallini’s GA group-specific mean \pm SE s[Cr] plots are valuable as representations of $s[\mathrm{Cr}]$ decline, but the curves are presented as mean $s[\mathrm{Cr}] \pm \mathrm{SEM}$, making it difficult to determine whether new $\mathrm{s}[\mathrm{Cr}]$ observations fall within the normal range or not. Thayyil et al. (11) provided tabular and graphic data on 161 infants of 22-28wk GA including mean and 10-90th percentile ranges for the first week of life (graphic) and age 0-8wk (tabular). Among those examined, the methodology and utility of the Thayyil study are most similar to this study. The mean values in the Thayyil's study by GA group parallel those of our study but are usually $10-15 \mu \mathrm{mol} / \mathrm{l}$ higher. These differences may result from the use of slightly different GA groups as well as from more inclusive entry criteria in the Thayyil study. The mean values in our study were also lower compared with several other studies, which may have included infants with risk factors for compromised renal function $(1,6,8,9,14)$. The exclusion criteria for these studies vary but overall were less strict than those of this study. Table 4 summarizes published studies, including their exclusion criteria and methodology $(1-3,6,8,9,11,14,20-28)$. The lower mean values in our study (and narrower variance estimates) may also result from adjustments due to the effects of covariates included in the predictive regression model, as well as due to the differences in $\mathrm{s}[\mathrm{Cr}]$ measurement methodology. The standardization of methodology is recent and occurred after most of the studies in Table 4 were published $(29,30)$.

Gentamicin was the only aminoglycoside antibiotic used in premature infants in our neonatal intensive care unit (NICU) during the study period. For infants treated longer than $72 \mathrm{~h}$, gentamicin dose was adjusted, if needed, according to serum drug level. The exposure was usually brief (Table 3 ). The frequency of gentamicin exposure was similar to that of aminoglycoside exposure in other NICUs $(31,32)$. Gentamicin impairs newborn renal function in term and preterm infants, increasing the fractional excretions of sodium, magnesium, calcium, and albumin (33-35). In cell cultures, gentamicin inhibits metanephron formation and reduces glomeruli number (36). In several clinical studies, the effect of gentamicin on $\mathrm{s}[\mathrm{Cr}]$ is unclear. Giapros et al. (35) demonstrated significant differences between preterm and full-term infants treated with gentamicin for $7 \mathrm{~d}$, but not between treated and untreated infants. Tugay et al. (34) showed significant differences between pretreatment, treatment, and post-treatment $\mathrm{s}[\mathrm{Cr}]$ values in preterm infants (mean \pm SD: $32.4 \pm 3.3 \mathrm{wk} \mathrm{GA}$ ) treated with gentamicin, but the difference was actually due
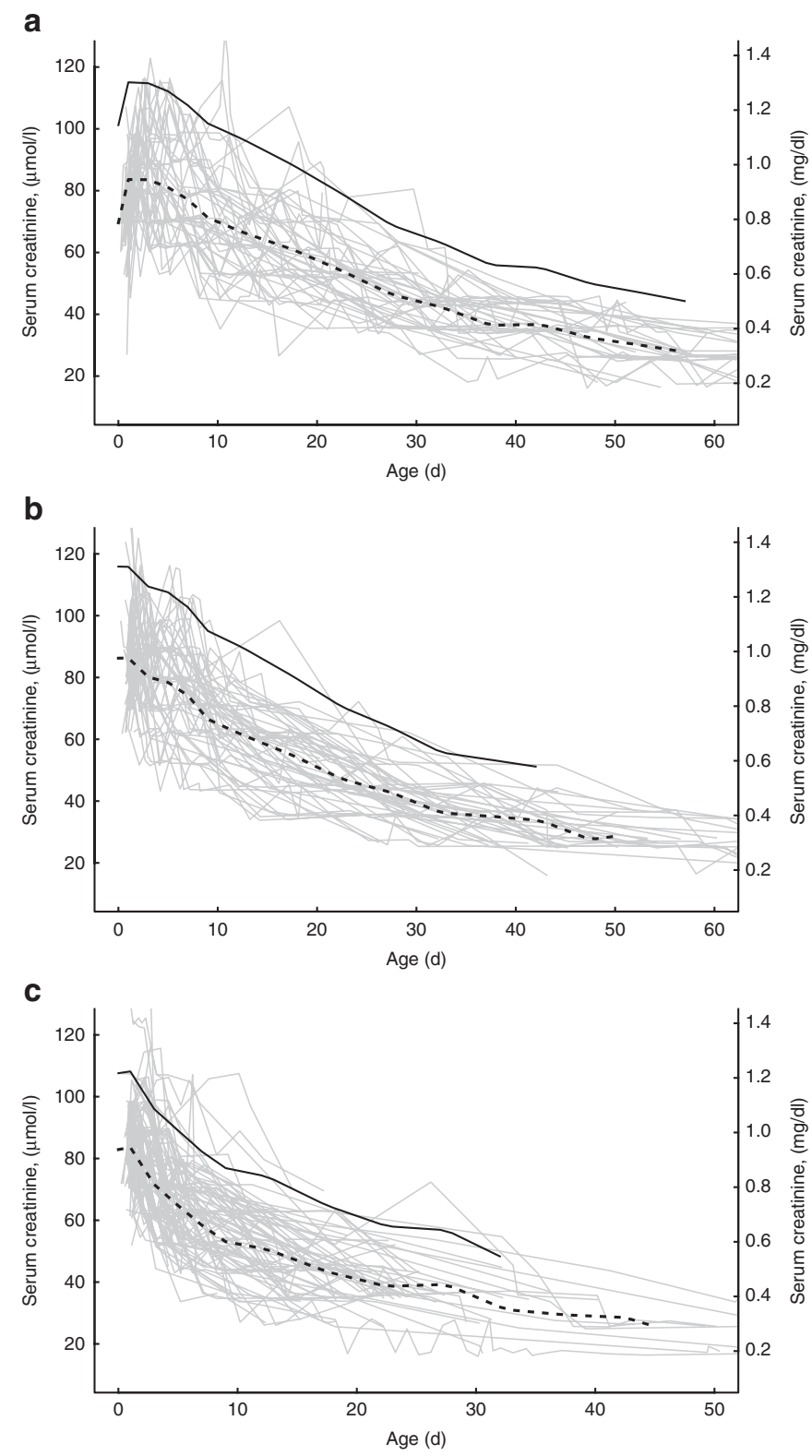

Figure 1. Predicted mean $\mathrm{s}[\mathrm{Cr}]$ (dashed line) and upper 95th percentile (solid line) for each GA group. The underlying light gray lines depict plots of each study infant. (a) GA group 25-27 wk. (b) GA group 28-29wk. (c) GA group 30-33 wk.

to a decline in $s[\mathrm{Cr}]$ after treatment, not due to an increase. In our data, the absence of measurable association between $s[\mathrm{Cr}]$ and gentamicin exposure in multivariate mixed-effects models may be related to the colinearity between the GA group and gentamicin exposure and to the low power to detect significant effects in subgroups.

Both antenatal steroid exposure and postnatal exposure to caffeine have been associated with increases in creatinine clearance and urine output $(37,38)$. Similar to gentamicin, antenatal steroid exposure was ubiquitous (Table 1) and no significant effect was noted in exploratory regression models. Caffeine was not administered routinely in study infants (see Methods); however, detailed data on caffeine receipt for individual infants 
Table 2. Predicted mean $\mathrm{s}[\mathrm{Cr}]$ and 95 th percentile values by chronological age and $\mathrm{GA}$ group

\begin{tabular}{|c|c|c|c|c|c|c|c|c|c|c|c|c|}
\hline \multirow[b]{3}{*}{ Age (d) } & \multicolumn{4}{|c|}{$25-27 w k$} & \multicolumn{4}{|c|}{$28-29 w k$} & \multicolumn{4}{|c|}{$30-33$ wk } \\
\hline & \multicolumn{2}{|c|}{$\mu \mathrm{mol} / \mathrm{l}$} & \multicolumn{2}{|c|}{$\mathrm{mg} / \mathrm{dl}$} & \multicolumn{2}{|c|}{$\mu \mathrm{mol} / \mathrm{I}$} & \multicolumn{2}{|c|}{$\mathrm{mg} / \mathrm{dl}$} & \multicolumn{2}{|c|}{$\mu \mathrm{mol} / \mathrm{l}$} & \multicolumn{2}{|c|}{$\mathrm{mg} / \mathrm{dl}$} \\
\hline & Mean & 95 PCTL & Mean & 95 PCTL & Mean & 95 PCTL & Mean & 95 PCTL & Mean & 95 PCTL & Mean & 95 PCTL \\
\hline $0-1$ & 84.0 & 114.9 & 0.95 & 1.30 & 86.6 & 115.8 & 0.98 & 1.31 & 84.0 & 107.8 & 0.95 & 1.22 \\
\hline $2-3$ & 84.0 & 114.9 & 0.95 & 1.30 & 80.4 & 111.0 & 0.91 & 1.26 & 71.6 & 99.1 & 0.81 & 1.12 \\
\hline $6-7$ & 76.9 & 108.7 & 0.87 & 1.23 & 74.3 & 103.9 & 0.84 & 1.18 & 58.3 & 83.9 & 0.66 & 0.95 \\
\hline $8-9$ & 71.6 & 103.2 & 0.81 & 1.17 & 66.3 & 97.0 & 0.75 & 1.10 & 53.0 & 78.2 & 0.60 & 0.88 \\
\hline $10-14$ & 66.3 & 97.3 & 0.75 & 1.10 & 61.0 & 90.3 & 0.69 & 1.02 & 50.4 & 74.1 & 0.57 & 0.84 \\
\hline $15-19$ & 61.0 & 89.1 & 0.69 & 1.01 & 54.8 & 81.4 & 0.62 & 0.92 & 43.3 & 65.9 & 0.49 & 0.75 \\
\hline $20-24$ & 53.9 & 79.9 & 0.61 & 0.90 & 46.9 & 71.8 & 0.53 & 0.81 & 38.9 & 59.2 & 0.44 & 0.67 \\
\hline $40-44$ & 37.1 & 54.8 & 0.42 & 0.62 & 33.6 & 51.6 & 0.38 & 0.58 & 28.2 & a & 0.32 & a \\
\hline $45-49$ & 32.7 & 50.6 & 0.37 & 0.57 & 28.8 & a & 0.33 & a & 24.1 & a & 0.27 & a \\
\hline $50-54$ & 30.1 & 47.3 & 0.34 & 0.54 & 29.2 & a & 0.33 & a & 25.0 & a & 0.28 & a \\
\hline $55-59$ & 27.4 & 44.9 & 0.31 & 0.51 & 28.8 & a & 0.33 & a & 22.2 & a & 0.25 & $\mathrm{a}$ \\
\hline
\end{tabular}

PCTL, percentile.

aecause of hospital discharges and lack of clinical need for testing, there were too few s[Cr]s to compute accurate variance estimates.

Table 3. Duration of gentamicin exposure by course and GA group

\begin{tabular}{lcccc}
\hline GA group & Ninfants & $\begin{array}{c}\text { Percent of infants } \\
\text { exposed to gentamicin }\end{array}$ & $\begin{array}{c}\text { Gentamicin exposure } \\
(\mathrm{d}) \text {, initial course }\end{array}$ & $\begin{array}{c}\text { Total gentamicin } \\
\text { exposure }(\mathrm{d})^{\mathrm{bc}}\end{array}$ \\
\hline $25-27 \mathrm{wk}$ & 44 & 95 & $4.35 \pm 2.67$ & $7.71 \pm 6.62$ \\
$28-29 \mathrm{wk}$ & 58 & 90 & $2.85 \pm 1.94$ & $4.31 \pm 3.78$ \\
$30-33 \mathrm{wk}$ & 116 & 66 & $1.80 \pm 1.66$ & $2.31 \pm 2.82$ \\
Overall & 218 & 78 & $3.12 \pm 2.21$ & $3.39 \pm 4.58$ \\
\hline
\end{tabular}

GA, gestational age.

${ }^{\mathrm{a} A n y}$ exposure at some time during hospitalization. ${ }^{\mathrm{b}}$ Results expressed as mean $\pm \mathrm{SD}$. Includes initial exposure.

in our study were not available; hence, its possible effects on $s[\mathrm{Cr}]$ behaviour remain unknown.

Other limitations deserve mention. Although it is one of the larger studies to explore $\mathrm{s}[\mathrm{Cr}]$ behaviour in VLBW infants, it includes a relatively small number of infants in the lowest GA group, and none less that 25-wk gestation. Infants of 23-24 wk GA are frequently exposed to potentially nephrotoxic medications and are more likely to have other risk factors for renal dysfunction. A reference range for $\mathrm{s}[\mathrm{Cr}]$ that strictly excludes infants with risk factors for renal impairment may not be attainable for this GA group. Our dataset also lacked detailed information on maternal conditions (e.g., hypertension, diabetes, use of nephrotoxic medications, placental insufficiency, and reason for preterm delivery) that might influence postnatal newborn renal function. The infants born to mothers with severe deteriorations in their renal function and very high initial $s[\mathrm{Cr}]$ levels might have patterns of $s[\mathrm{Cr}]$ decline that deviated substantially from our nomograms simply because of the higher initial creatinine load (17). However, although $s[\mathrm{Cr}]$ at birth reflects maternal renal function, peak $\mathrm{s}[\mathrm{Cr}]$ in the first few days of life is a function of newborn factors, particularly GA (9). In Table 1, we have characterized $s[\mathrm{Cr}]$ in the first 24-h age for each GA group. Finally, an unequal distribution of small for gestational age (SGA, BW $<10$ th percentile for GA (39)) is noted in Table 1, reflecting the use of an arbitrary cutoff $(\mathrm{BW}<1,500 \mathrm{~g})$ as the upper inclusion value for the study. To correct for this inequality, we included BW in the predictive model.

In summary, our study offers clinically useful nomograms with age-specific prediction intervals adjusted to permit assessment of $s[\mathrm{Cr}]$ trends as a function of GA in VLBW infants from birth through 34-36-wk PMA. It differs from prior studies in its strict exclusion of infants with risk factors for renal impairment, in its relatively large size, and in its use of regression models with locally derived variance estimates to establish an upper $95 \%$ prediction interval. Monitoring $s[\mathrm{Cr}]$ trends in VLBW infants may be useful in identifying infants who require special attention to fluid and electrolyte 


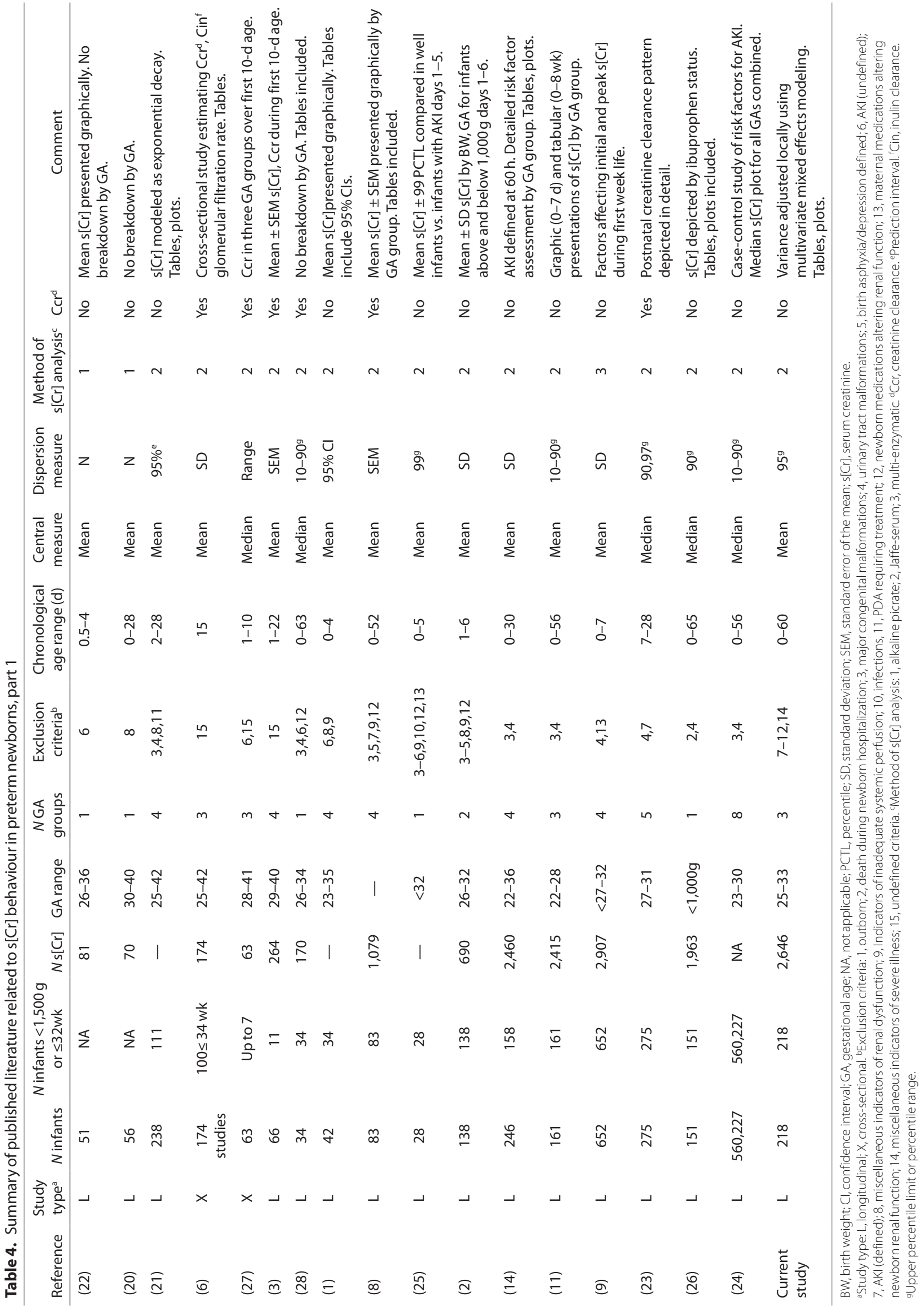


balance, dosing of potentially toxic medications metabolized or excreted by the kidney, and those who are at risk for longterm renal impairment.

\section{METHODS}

\section{Study Subjects}

We retrospectively identified a sample of 218 inborn VLBW appropriate-for-gestational age infants with $\mathrm{BW}<1,500 \mathrm{~g}$ and uncomplicated clinical courses born at Morgan Stanley Children's Hospital of New York-Presbyterian from July 2005 through December 2009. These infants were selected from a dataset that included all 831 inborn VLBW infants admitted to the NICU during that period. The additional inclusion criteria were daily urine output $>1 \mathrm{ml} / \mathrm{kg} / \mathrm{h}$ and survival to discharge. The exclusion criteria were major congenital malformations, including obstructive uropathies and a diagnosis of or risk factors associated with AKI (14). The latter included lactic acidosis and/or hypotension requiring treatment; respiratory distress requiring mechanical ventilation beyond the first 6-d of age; sepsis (defined as a positive culture from blood or body fluids and/or treatment with antibiotics for $\geq 5 \mathrm{~d}$ ); urinary tract infection (defined similarly), medical, or surgical therapy for a patent ductus arteriosus; necrotizing enterocolitis (defined by the radiographic presence of pneumatosis intestinalis, free gas, portal gas, or surgical pathology); spontaneous intestinal perforation; and treatment with potentially nephrotoxic drugs: e.g., vancomycin, indomethacin, and amphotericin. Treatment with gentamicin could not be an exclusion criterion because $90 \%$ (752/831) of potential study infants received gentamicin for at least $48 \mathrm{~h}$. Charts were reviewed and eligible infants were identified by a single experienced neonatologist. All eligible infants born during the study interval were included. The study was approved by the Columbia University Medical Center Institutional Review Board, who granted a waiver of consent.

\section{Fluid and Electrolyte Management of Infants}

The infants were cared for in heated, humidified, incubators servocontrolled to an abdominal skin temperature of $36.0-36.5^{\circ} \mathrm{C}$, with a relative humidity of $60 \%$. Initially, intravenous (i.v.) fluid volume was $80-100 \mathrm{ml} / \mathrm{kg} / \mathrm{d}$ during the first $24 \mathrm{~h}$ of life, increasing progressively to $120 \mathrm{ml} / \mathrm{kg} / \mathrm{d}$ by $48-72-\mathrm{h}$ age. Serum electrolytes, as well as serum creatinine, urea, glucose, calcium, phosphorous, and magnesium, were usually measured 1-3 times daily in the first few days of life and less frequently thereafter, as clinically indicated. Sodium was usually not added to the i.v. fluids until the third day of life. Small-volume enteral feeds using expressed human milk or formula were initiated as soon as infants achieved cardiorespiratory stability; the volume of i.v. fluid given was readjusted to compensate for slowly increasing enteral intake. The fluid intake and urine output were recorded hourly; weight was measured daily. The intravenous fluid intake was discontinued when infants achieved $100 \mathrm{ml} / \mathrm{kg} / \mathrm{d}$ of enteral intake; the feeds were progressively advanced, thereafter, to a volume of $160 \mathrm{ml} /$ $\mathrm{kg} / \mathrm{d}$. Caffeine was not administered routinely, but was started only for infants with frequent apneic episodes accompanied by oxygen desaturation or bradycardia requiring intervention with stimulation or additional supplemental oxygen.

\section{Creatinine Measurement}

All $s[\mathrm{Cr}] \mathrm{s}$ obtained during the normal course of care during the first $60 \mathrm{~d}$ of age were included in the analyses. S[Cr] was measured using a kinetic modification of the Jaffe method on AU 2700 and AU 640 analyzers (Beckman Coulter, Brea, CA). The method of analysis remained unchanged during the study period. The results conformed to standard values generated by isotope dilution mass spectrometry (29). The manufacturer reports no significant interference (within 10\% of initial value) for serum bilirubin levels up to $342 \mu \mathrm{mol} / \mathrm{l}$ (Creatinine, General Chemistry OSR BAOSR6×78.02, Beckman Coulter).

\section{Gentamicin Exposure}

Days of gentamicin exposure for each infant were measured as the number of days between the initial dose and the discontinuation order for the medication, rounded up to whole days. Gentamicin exposure was divided into initial and total. The initial exposure occurred during the first $7 \mathrm{~d}$ of age, almost always beginning within several hours of birth, and was often discontinued by the third day of life. The total exposure included the number of days of initial exposure plus additional days of exposure during the remainder of an infant's hospitalization.

\section{Statistical Analysis}

There were multiple $s[\mathrm{Cr}]$ measurements, including multiple measurements per day in the first weeks of life for each infant. The measurement of $s[\mathrm{Cr}]$ is included in "basic metabolic panel" of blood chemistries (sodium, potassium, chloride, total $\mathrm{CO}_{2}$, blood urea nitrogen, glucose, calcium, and creatinine) that are usually monitored more frequently in the earlier portion of a VLBW infant's hospitalization, when the risk of abnormalities in fluid and electrolyte balance and acid-base status is highest, and less frequently as the infant matures and successfully adapts to extrauterine life. To estimate the mean $s[\mathrm{Cr}]$ profile, the infants were grouped according to GA week from 25 through 33, then divided into three groups based on similarities in the mean GA profile: $25-27,28-29$, and 30-33 wk. For each GA group, the mean $\mathrm{s}[\mathrm{Cr}]$ profile was estimated without assumptions about the shape of the profile curve, using lowess smooth, a locally weighted scatterplot smoother ( $\mathrm{R}$ : A language and environment for statistical computing. R Foundation for Statistical Computing, Vienna, Austria) (40).

We used a mixed-effects linear model to estimate the upper boundary of the $95 \%$ prediction interval for $s[\mathrm{Cr}]$. The mean $s[\mathrm{Cr}]$ was modeled at $2-\mathrm{d}$ intervals for the first $10 \mathrm{~d}$ of life, when the mean curve changed most rapidly, and at 5-d intervals thereafter. The fixed effects were age intervals, GA group, an age-GA group interaction, and adjustors: total gentamicin received, BW, and gender. A random mean for each infant during each age interval was added to the model because most infants had multiple measurements within each age interval; this allowed the model to adapt to changes in variance of these random effects with age. Total infant variances in each age interval were pooled across GA groups to estimate the population variances by age. These variance estimates were smoothed and used with each GA group mean to estimate the upper 95\% prediction intervals for $s[\mathrm{Cr}]$ by GA group. In order that trends of elevated $s[\mathrm{Cr}]$ could be assessed, the interval limit was computed to require three or more contiguous elevated $\mathrm{s}[\mathrm{Cr}]$ measurements to be considered above the $95 \%$ prediction range.

\section{STATEMENT OF FINANCIAL SUPPORT}

No financial assistance was received in support of this study.

Disclosure: The authors have no conflicts of interest and no financial relationships relevant to this article to disclose.

\section{REFERENCES}

1. Miall LS, Henderson MJ, Turner AJ, et al. Plasma creatinine rises dramatically in the first 48 hours of life in preterm infants. Pediatrics 1999;104:e76.

2. Auron A, Mhanna MJ. Serum creatinine in very low birth weight infants during their first days of life. J Perinatol 2006;26:755-60.

3. Bueva A, Guignard JP. Renal function in preterm neonates. Pediatr Res 1994;36:572-7.

4. Pitkin RM, Reynolds WA. Creatinine exchange between mother, fetus, and amniotic fluid. Am J Physiol 1975;228:231-7.

5. Arant BS Jr. Postnatal development of renal function during the first year of life. Pediatr Nephrol 1987;1:308-13.

6. Brion LP, Fleischman AR, McCarton C, Schwartz GJ. A simple estimate of glomerular filtration rate in low birth weight infants during the first year of life: noninvasive assessment of body composition and growth. J Pediatr 1986;109:698-707.

7. Coulthard MG. Maturation of glomerular filtration in preterm and mature babies. Early Hum Dev 1985;11:281-92.

8. Gallini F, Maggio L, Romagnoli C, Marrocco G, Tortorolo G. Progression of renal function in preterm neonates with gestational age $\leq 32$ weeks. Pediatr Nephrol 2000;15:119-24.

9. Iacobelli S, Bonsante F, Ferdinus C, Labenne M, Gouyon JB. Factors affecting postnatal changes in serum creatinine in preterm infants with gestational age $<32$ weeks. J Perinatol 2009;29:232-6. 
10. Modi N. Development of renal function. Br Med Bull 1988;44:935-56.

11. Thayyil S, Sheik S, Kempley ST, Sinha A. A gestation- and postnatal agebased reference chart for assessing renal function in extremely premature infants. J Perinatol 2008;28:226-9.

12. Black MJ, Sutherland MR, Gubhaju L. Effects of preterm birth on the kidney. In: Sahay M, ed. Basic Nephrology and Acute Kidney Injury. Rijeka, Croatia: In Tech, 2012:1-29.

13. Jetton JG, Askenazi DJ. Update on acute kidney injury in the neonate. Curr Opin Pediatr 2012;24:191-6.

14. Cuzzolin L, Fanos V, Pinna B, et al. Postnatal renal function in preterm newborns: a role of diseases, drugs and therapeutic interventions. Pediatr Nephrol 2006;21:931-8.

15. Black MJ, Sutherland MR, Gubhaju L, Kent AL, Dahlstrom JE, Moore L. When birth comes early: effects on nephrogenesis. Nephrology (Carlton) 2013;18:180-2.

16. Gubhaju L, Sutherland MR, Yoder BA, Zulli A, Bertram JF, Black MJ. Is nephrogenesis affected by preterm birth? Studies in a non-human primate model. Am J Physiol Renal Physiol 2009;297:F1668-77.

17. Lao TT, Loong EP, Chin RK, Lam YM. Renal function in the newborn. Newborn creatinine related to birth weight, maturity and maternal creatinine. Gynecol Obstet Invest 1989;28:70-2.

18. Larsson A, Palm M, Hansson LO, Axelsson O. Reference values for clinical chemistry tests during normal pregnancy. BJOG 2008;115:874-81.

19. Guignard JP, Drukker A. Why do newborn infants have a high plasma creatinine? Pediatrics 1999;103:e49.

20. Feldman H, Guignard JP. Plasma creatinine in the first month of life. Arch Dis Child 1982;57:123-6.

21. Rudd PT, Hughes EA, Placzek MM, Hodes DT. Reference ranges for plasma creatinine during the first month of life. Arch Dis Child 1983;58:212-5.

22. Stonestreet BS, Oh W. Plasma creatinine levels in low-birth-weight infants during the first three months of life. Pediatrics 1978;61:788-9.

23. Vieux R, Hascoet JM, Merdariu D, Fresson J, Guillemin F. Glomerular filtration rate reference values in very preterm infants. Pediatrics 2010;125:e1186-92.

24. Walker MW, Clark RH, Spitzer AR. Elevation in plasma creatinine and renal failure in premature neonates without major anomalies: terminology, occurrence and factors associated with increased risk. J Perinatol 2011:31:199-205.

25. Choker G, Gouyon JB. Diagnosis of acute renal failure in very preterm infants. Biol Neonate 2004;86:212-6.

26. George I, Mekahli D, Rayyan M, Levtchenko E, Allegaert K. Postnatal trends in creatinemia and its covariates in extremely low birth weight (ELBW) neonates. Pediatr Nephrol 2011;26:1843-9.

27. Gordjani N, Burghard R, Leititis JU, Brandis M. Serum creatinine and creatinine clearance in healthy neonates and prematures during the first 10 days of life. Eur J Pediatr 1988;148:143-5.

28. Sonntag J, Prankel B, Waltz S. Serum creatinine concentration, urinary creatinine excretion and creatinine clearance during the first 9 weeks in preterm infants with a birth weight below 1500 g. Eur J Pediatr 1996;155:815-9.
29. Myers GL, Miller WG, Coresh J, et al.; National Kidney Disease Education Program Laboratory Working Group. Recommendations for improving serum creatinine measurement: a report from the Laboratory Working Group of the National Kidney Disease Education Program. Clin Chem 2006;52:5-18.

30. Peake M, Whiting M. Measurement of serum creatinine-current status and future goals. Clin Biochem Rev 2006;27:173-84.

31. Alexander VN, Northrup V, Bizzarro MJ. Antibiotic exposure in the newborn intensive care unit and the risk of necrotizing enterocolitis. J Pediatr 2011;159:392-7.

32. Liem TB, Krediet TG, Fleer A, Egberts TC, Rademaker CM. Variation in antibiotic use in neonatal intensive care units in the Netherlands. J Antimicrob Chemother 2010;65:1270-5.

33. Giapros VI, Cholevas VI, Andronikou SK. Acute effects of gentamicin on urinary electrolyte excretion in neonates. Pediatr Nephrol 2004;19:322-5.

34. Tugay S, Bircan Z, Cağlayan C, Arisoy AE, Gökalp AS. Acute effects of gentamicin on glomerular and tubular functions in preterm neonates. Pediatr Nephrol 2006;21:1389-92.

35. Giapros VI, Andronikou SK, Cholevas VI, Papadopoulou ZL. Renal function and effect of aminoglycoside therapy during the first ten days of life. Pediatr Nephrol 2003;18:46-52.

36. Cullen LA, Young RJ, Bertram JF. Studies on the effects of gentamicin on rat metanephric development in vitro. Nephrology 2000;5:115-23.

37. Crossley KJ, Allison BJ, Polglase G, et al. Effects of caffeine on renal and pulmonary function in preterm newborn lambs. Pediatr Res 2012;72: $19-25$.

38. Jahnukainen T, Chen M, Berg U, Celsi G. Antenatal glucocorticoids and renal function after birth. Semin Neonatol 2001;6:351-5.

39. Fenton TR, Kim JH. A systematic review and meta-analysis to revise the Fenton growth chart for preterm infants. BMC Pediatr 2013;13:59.

40. Cleveland WS, Grosse E, Shyu WM. Local regression models. In: Chambers JM, Hastie TJ, eds. Statistical Models in S. Pacific Grove, CA: Wadsworth \& Brooks/Cole, 1992:309-76.

(c)(1)(2)

This work is licensed. under a Creative Commons Attribution-NonCommercial-ShareAlike $\quad 4.0$ International License. The images or other third party material in this article are included in the article's Creative Commons license, unless indicated otherwise in the credit line; if the material is not included under the Creative Commons license, users will need to obtain permission from the license holder to reproduce the material. To view a copy of this license, visit http://creativecommons.org/licenses/ by-nc-sa/4.0/ 